\title{
Corrigendum: ER network dynamics are differentially controlled by myosins XI-K, XI-C, XI-E, XI-I, XI-1, and XI-2
}

\section{Hong-Bo Gao*}

Biosciences, CLES, Exeter University, Exeter, UK

${ }^{*}$ Correspondence: h.gao@exeter.ac.uk

Edited and reviewed by:

Dan Szymanski, Purdue University, USA

Keywords: endoplasmicreticulum, movement, myosin, persistencymapping, dynamics, remodeling

\section{A corrigendum on}

ER network dynamics are differentially controlled by myosins XI-K, XI-C, XI-E, XI-I, XI-1, and XI-2

by Griffing, L. R., Gao, H. T., and Sparkes, I. (2014). Front. Plant Sci. 5:218. doi: 10.3389/fpls.2014.

00218

In the article "ER network dynamics are differentially controlled by myosins XI-K, XI-C, XI-E, XI-I, XI-1, and XI2," published 21 May 2014, with myself as the second author has a mis-spelling/ mis-formatting of my name.

Currently my name is spelled as: Hongbo T. Gao.

The correct spelling is: Hong-Bo Gao (Initial, H. B. Gao). I did not notice this mistake during the review process.

Conflict of Interest Statement: The author declares that the research was conducted in the absence of any commercial or financial relationships that could be construed as a potential conflict of interest.

Received: 15 October 2014; accepted: 27 October 2014; published online: 12 November 2014.
Citation: Gao H-B (2014) Corrigendum: ER network dynamics are differentially controlled by myosins XIK, XI-C, XI-E, XI-I, XI-1, and XI-2. Front. Plant Sci. 5:637. doi: 10.3389/fpls.2014.00637

This article was submitted to Plant Cell Biology, a section of the journal Frontiers in Plant Science.

Copyright (c) 2014 Gao. This is an open-access article distributed under the terms of the Creative Commons Attribution License (CC BY). The use, distribution or reproduction in other forums is permitted, provided the original author(s) or licensor are credited and that the original publication in this journal is cited, in accordance with accepted academic practice. No use, distribution or reproduction is permitted which does not comply with these terms. 